\title{
The Effect Of Air Gap Distance Variation Between Stator And Rotor In Permanent Magnet Generator With Low Rotation Multi-Disc Axial Flux
}

\author{
Yusuf Ismail Nakhoda a,1,*, Choirul Saleh a,2, \\ a Electrical Engineering, National Institute of Technology Malang, Indonesia \\ ${ }^{1}$ yusuf nakhoda@lecturer.itn.ac.id *; ${ }^{2}$ choirulsaleh@lecturer.itn.ac.id; \\ * corresponding author
}

\section{ABSTRACT}

Keywords

Permanent_magnet

Generator

Axial_flux

Air_gap

Multi_disc

Low rotation
This axial flux permanent magnet generator was designed in low speed multi-disc using two stator discs and three rotor discs, wherein each rotor disc contained ten poles of Neodynium type permanent magnet and each stator had ten coils, in order to be able to produce $600 \mathrm{rpm}$ generator rotation. The voltage prepared in each stator phase output would later be connected in series or parallel circuit for testing. This generator was tested with variations of air gap between different rotors and stators. There were four variations of air gap which were $2 \mathrm{~mm}, 3 \mathrm{~mm}, 4 \mathrm{~mm}$, and $5 \mathrm{~mm}$ and each of them were connected to stator circuit in series. The test results with an air gap of $2 \mathrm{~mm}$ generated voltage of 59 Volt AC, an air gap of $3 \mathrm{~mm}$ generated a voltage of 53.7 Volt AC, an air gap of $4 \mathrm{~mm}$ generated a voltage of 49.6 Volt AC, an air gap of $5 \mathrm{~mm}$ generated a voltage of 48.5 Volt AC. Based on the test results, it can be concluded that the gap of the air gap was inversely proportional to the output voltage, the greater the value of the air gap that was applied, the smaller the voltage generator output was generated

\section{Introduction}

Nowadays, citizen growth is higly rapid and it is accompanied with housing growth, both of which result in electricity provider must increase power capacity more than what is available now. Therefore, generator innovation or micro scale generator emerges which is considered supportive to some circles [1]. Generator as the pioneer activator is still minimum in its utilization mainly in areas of Indonesia that have abundant renewable energy source which is water energy and it has not been fully utilized. Microhydro power plant is the type of renewable power plant that is environmentally friendly, easy to operate, and low in operational cost. The preliminary survey result exhibited that rivers in Manokwari, Indonesia carried hydraulic potential approximately $29.5 \mathrm{~kW}$. According to the result, microhydro power plant would be arranged in this location. The power plant would employ $25.2 \mathrm{~kW}$ hydraulic potential based on flow rate of $0.3 \mathrm{~m} 3 / \mathrm{s}$ and head height of $8.6 \mathrm{~m} \mathrm{[2].}$

Utilization of micro scale generator is considered to be supportive if it is well-developed since it is easily maintained and controlled, and its materials are easy to obtain [3],[4],[5]. The available generator in the market today is the generator which possesses high Rpm and requires preliminary electrical energy to create its magnetic field. Harmonic step-time generator model was applied into induction and mechanical rotor in electrical generator to estimate faults and propose simple closed form of analytic expression as an illustration. The prediction then was validated by testing the rig in $30 \mathrm{~kW}$ induction generator [6].

The generator made for this research is affordable and easy to maintain. Axial flux generator type is the one that is expected to be developed. Axial flux permanent magnet synchronous generator (PMSG) was designed the as double stators and three rotors, electromagnetic characteristic and analyzed structural. Designing aimed for axial flux generator to be placed in single tip from side motor of the machine and permanent magnet to be placed in double tip of middle rotor. More than one motor 
out of the total of stators was applied here [7],[8]. This generator with axial flux permanent magnet of four stators, four rotors, one phase was able to assist for generating energy since it was activated with one axis and also it produced one phase in every one side of stators [9],[10].

In its utilization, it can be implemented to water turbine in low current. Nowadays, renewable energy is varied in the development and creation of all sorts of applications [11]. With a shape like a disc, it simplifies the production with variation of permanent magnet and the more number in winding, then the voltage will improve [12,[13].

The number of stators and rotors is going to affect the output of generated created and the more stators and rotors available, the output will be more as well, and one generator possesses many outputs that can be used in implementation [14].

The air gap width of axial flux wound rotor (AFWR) synchronous generator needs to be determined presicely in accordance with the design parameter. One of the advantages of axial flux (AF) machine is its air gap is adjustable. AF generator performance can be arranged by adjusting its air gap [5].

This research described the performance of permanent magnet generator with axial flux multi-disc that used two stator discs and three rotor discs where every rotor disc was found with ten Neodynium type permanent magnet poles and every stator is found with ten coils which were tested with four different air gap variation between rotor and stator.

\section{The Proposed Method/Algorithm}

\subsection{Planning Out the Generator Rotation Speed}

Stator coil (stator is an alternator component that function for producing alternating current (AC)) was installed permanently in stator core and attached to its host, thus it did not go rotating (static).

This stator coil consisted of ten insulated wire winding which were wounded to slots around the stator core. Every winding had equal number of twisted. The correlation between stator rotation field speed (rpm) and generator frequency, which was inversely proportional to the number of poles based on the rotation per minute, could be determined with the equation below:

$$
n_{g}=\frac{120 \times f}{p}(r p m)
$$

$n_{g}$ is generator rotation (rpm), $\mathrm{f}$ is frequency $(\mathrm{Hz})$ and $\mathrm{p}$ is the number of magnet poles in stator.

\subsection{Permanent Magnet Rotor}

Designing this rotor utilized rotor made of acrylic layered aluminum with a diameter of $30 \mathrm{~cm}^{2}$. The designed rotor could accommodate ten pieces of poles with magnet. This designing of axial flux generator rotor utilized Neodynium magnet by determining the quantities using equations as follow:

\subsection{Maximum Flux Density}

The value of maximum magnet flux is:

$$
B_{\text {max }}=B_{r} \times \frac{L_{m}}{L_{m}+\delta}(T)
$$

Where $B_{\max }$ represents flux density (T), $B_{r}$ is Residual Induction (T), $L_{m}$ is the height of a magnet $(\mathrm{m})$ and $\delta$ is air gap distance $(\mathrm{m})$.

\subsection{Magnetic Field Area}

The placement design for permanent magnet in generator rotor used equation as below:

$$
A_{\text {magn }}=\frac{\pi\left(r o^{2}-r i^{2}\right)-\tau f(r o-r i) N_{m}}{N_{m}}\left(m^{2}\right)
$$

$A_{\text {magn }}$ is magnet area $\left(\mathrm{m}^{2}\right), \pi$ is phi (3.14 atau 22/7), ri represents magnetic radius within the magnet (m), ro is magnetic radius outside magnet (m), $\tau f$ is distance between magnet (m) and $N_{m}$ is the number of magnet. 


\subsection{Maximum Flux}

In order to Fig. out maximum flux out of permanent magnet, it applied the equation as follows:

$\emptyset_{\text {max }}=A_{\text {magn }} \times B_{\max }(W b)$

$\emptyset_{\max }$ is the maximum flux (Wb), $A_{\text {magn }}$ is magnetic area $\left(\mathrm{m}^{2}\right)$ and $B_{\max }$ is flux density (T).

\subsection{The Number of Stator Coil}

In order to Fig. out the number of stator coil (Ns) needed for its stator, it applied the equation as follows:

$N_{s}=p \times \frac{N_{p h}}{2}$.

$N_{s}$ is the number of stator coil, $N_{p h}$ is the number of phase, and $\mathrm{p}$ is the number of magnetic pole.

\subsection{The Number of Stator Winding}

Copper wire is one of the many types of electrical conductors based on the material. This type of wire was the first metal used as cables material. The copper wire function is often used for winding material in electric generators. Determining the number of winding (n) was one of the most important things in designing the axial flux generator in which the number of winding was afftected by several parameters; the number of coil and phase, frequency, and maximum flux.

\subsection{Induction Voltage}

While for voltage from generator induction in generator that is being generated can be calculated by below equation:

$$
E_{r m s}=4.44 \times N \times f \times \emptyset_{\max } \times \frac{N_{s}}{N_{p h}}(\text { Volt }) .
$$

$E_{r m s}$ is the voltage from generator induction (Volt), $\mathrm{N}$ represents the number of winding, $\mathrm{F}$ is the frequency (Hertz), $\varnothing_{\max }$ is the maximum flux (Wb), $\mathrm{N}_{\mathrm{s}}$ is the number of stator coil and $N_{p h}$ is the number of phase.

\subsection{Single Phase Power Generator}

While to Fig. out the power out of generator that is being generated can be calculated by below equation:

$$
S_{1 \varnothing}=V_{L-N} \times I(V A)
$$

In the above equation, $S_{1 \emptyset}$ is the power generator (VA), $V_{L-N}$ is the voltage generator (Volt), and I represents the current (Ampere).

\section{Method}

Based on the above equations, this generator design was designed to work in frequency of $50 \mathrm{~Hz}$ and rotate with speed of $600 \mathrm{rpm}$. The output voltage was designed in 49.1 Volt in a state without load. By using rotors made of aluminum layered acrylic with diameter of $30 \mathrm{~cm} 2$, the rotor was designed to fit ten pieces of Neodynium magnetic poles. The rotor was fashioned in order to be able for the permanent magnet to be placed in such a way, to determine the distance between magnets and rotor circumference, and to Fig. out the number of magnet in accordance with its poles. Distance between magnets and rotor radius as well as $80 \mathrm{~cm}$ rotor disc circumference is depicted in Fig. 1 (a). There were ten pieces of coil windings in rotor. This number was generated from the amount of magnets in the rotor in order that stator circumference conformed to rotor circumference. Another consideration was for the coils to be able to be fully passed through by magnetic flux. The number of of stator coil (Ns) needed for the stator used two Nph (phase and neutral) and p used ten poles, while the geometry of permanent magnet rotor with ten pieces of coils each of which consisted of 142 windings and this is depicted in Fig. 1 (b). 


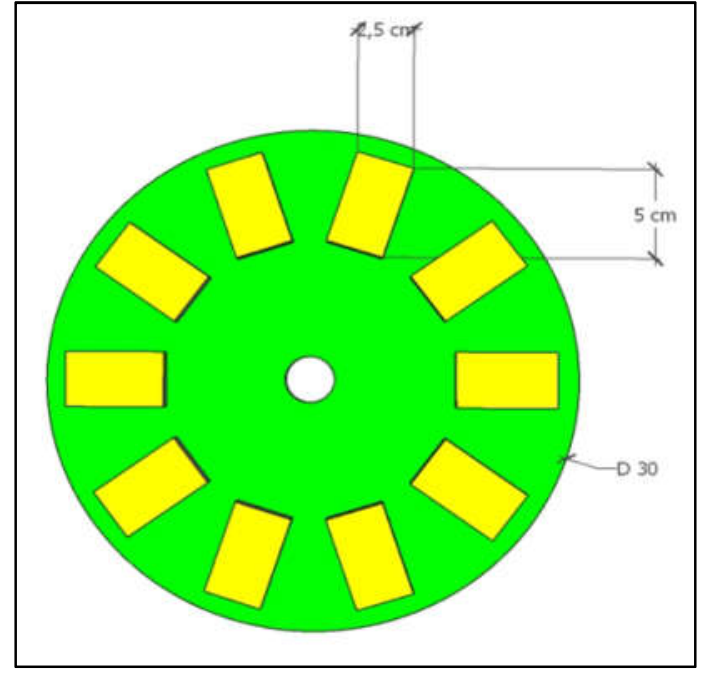

(a)

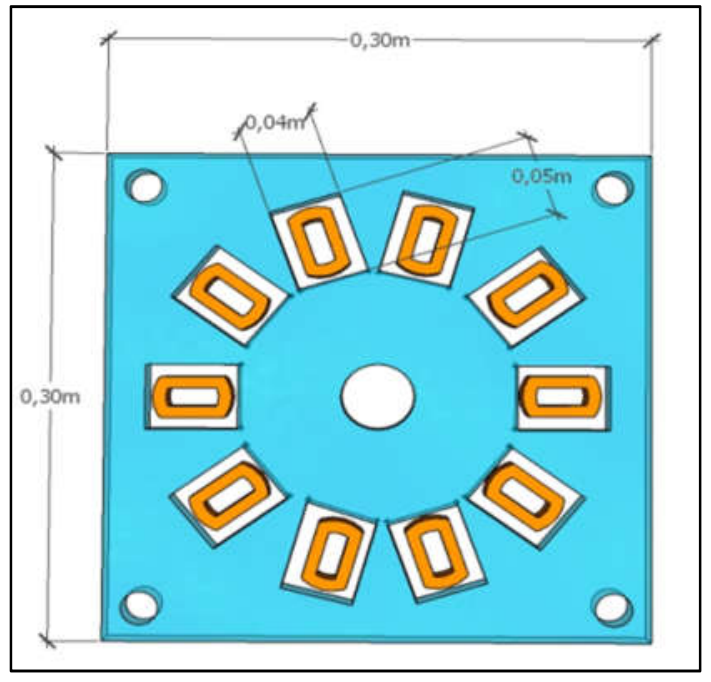

(b)

Fig. 1. (a). Axial Flux Permanent Magnet Generator Rotor Geometry, (b). Generator Stator without Iron Core

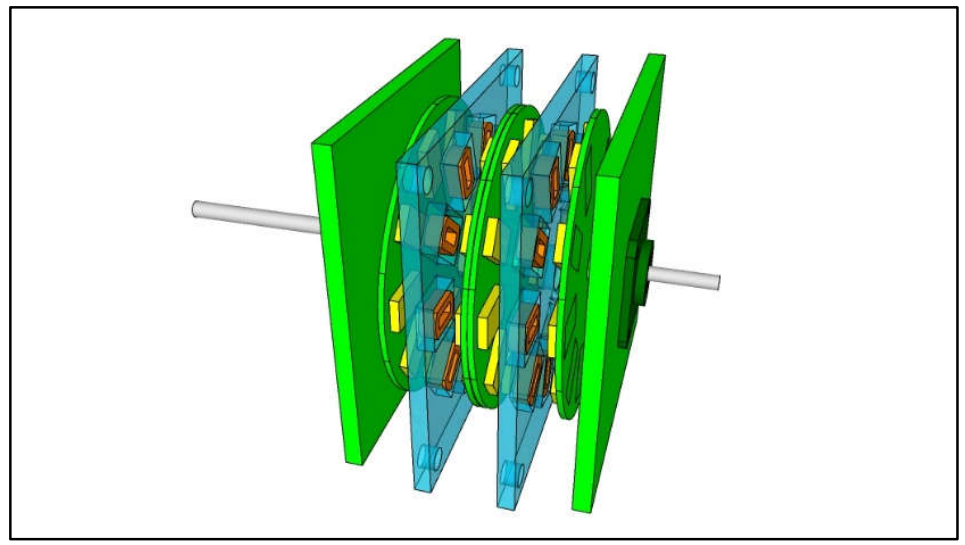

Fig. 2. Design for Permanent Magnet Generator with Multi-Disc Axial Flux

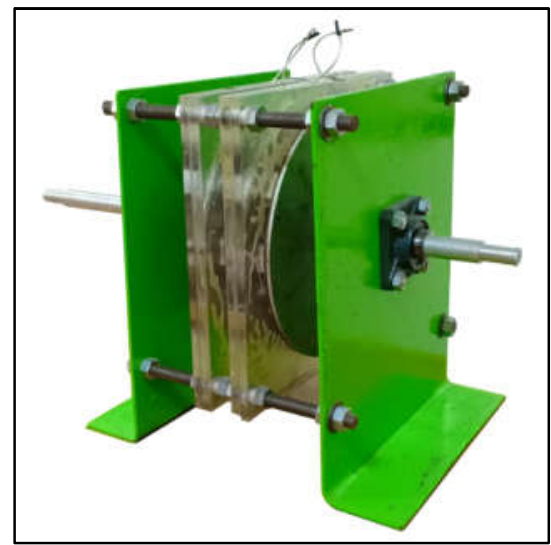

Fig. 3.Fig. 3. Prototype Assembly Result of Permanent Magnet Generator with Multi-Disc Axial Flux 


\section{Results and Discussion}

Testing the permanent magnet generator of multi-disc axial flux with three rotors, two stators with variation of air gap aimed to figure out thre result comparison out of generator outline and generator measurement. Generator testing and measurement were set a place in ITN Malang Electric Energy Conversion Laboratory. This generator was tested with variation of air gap between different rotors and stators. There were four variation of air gap which were $2 \mathrm{~mm}, 3 \mathrm{~mm}, 4 \mathrm{~mm}$, and $5 \mathrm{~mm}$. Each of differed air gap was connected to stator sequences in series circuit.

\subsection{Testing with Four Variation of Air Gap}

The template is designed so that author affiliations are not repeated each time for multiple authors of the same affiliation. Please keep your affiliations as succinct as possible (for example, do not differentiate among departments of the same organization). This template was designed for two affiliations.

Table 1. Generator Test Result with 5 mm Air Gap

\begin{tabular}{|c|c|c|c|c|c|c|c|}
\hline \multirow{2}{*}{ No } & \multirow{2}{*}{ Rpm } & \multicolumn{2}{|c|}{$\begin{array}{c}\text { Output } \\
\text { Voltage with No Load }\end{array}$} & \multicolumn{4}{|c|}{ Output Voltage Connected with Battery } \\
\hline & & $\begin{array}{l}\text { Volt } \\
\text { AC }\end{array}$ & $\begin{array}{l}\text { Volt } \\
\text { DC }\end{array}$ & $\begin{array}{l}\text { Volt } \\
\text { AC }\end{array}$ & $\begin{array}{l}\text { Volt } \\
\text { DC }\end{array}$ & $\begin{array}{l}\text { Current } \\
\text { (A) }\end{array}$ & $\begin{array}{c}\text { Volt } \\
\text { Battery }\end{array}$ \\
\hline 1 & 50 & 4.2 & 3.9 & 4,2 & 3.9 & 0 & 12.1 \\
\hline 2 & 100 & 8.2 & 7.3 & 8,2 & 7.3 & 0 & 12.1 \\
\hline 3 & 150 & 12 & 10.7 & 9,6 & 12.2 & 0.03 & 12.2 \\
\hline 4 & 200 & 16.1 & 14.4 & 10,3 & 12.3 & 0.08 & 12.3 \\
\hline 5 & 250 & 20.3 & 18.3 & 11 & 12.4 & 0.13 & 12.4 \\
\hline 6 & 300 & 24.3 & 21.9 & 11,8 & 12.7 & 0.20 & 12.7 \\
\hline 7 & 350 & 28.2 & 25.5 & 12,3 & 12.9 & 0.26 & 12.9 \\
\hline 8 & 400 & 32.3 & 29.3 & 13 & 13 & 0.35 & 13.2 \\
\hline 9 & 450 & 37.1 & 34.6 & 13,7 & 13.5 & 0.43 & 13.5 \\
\hline 10 & 500 & 40.2 & 36.5 & 14,2 & 13.8 & 0.49 & 13.8 \\
\hline 11 & 550 & 44.1 & 40.6 & 14,7 & 14.1 & 0.54 & 14.1 \\
\hline 12 & 600 & 48.5 & 44.4 & 15,4 & 14.3 & 0.65 & 14.3 \\
\hline
\end{tabular}

Data obtained from the measurement result was that the rotation speed was from 50 to $600 \mathrm{rpm}$. With this rotation speed, the highest voltage obtained in $600 \mathrm{rpm}$ and $5 \mathrm{~mm}$ air gap was 48.5 Volt AC and generator work frequency was in $50 \mathrm{~Hz}$.

In air gap variation of $5 \mathrm{~mm}$, the generator was able to charge battery in minimum rotation of 350 rpm with voltage produced was 12.9 Volt DC and current flowed was 0.26 Ampere.

Table 2.

Generator Test Result with 4 mm Air Gap

\begin{tabular}{cccc|cccc}
\hline & & \multicolumn{2}{c|}{ Output Voltage with No Load } & \multicolumn{3}{c}{ Output Voltage Connected with Battery } \\
\cline { 3 - 7 } No. & Rpm & Volt AC & Volt DC & Volt AC & Volt DC & Current (A) & $\begin{array}{c}\text { Volt } \\
\text { Battery }\end{array}$ \\
\hline 1 & 50 & 4.3 & 4.0 & 4.3 & 4.0 & 0 & 12.2 \\
2 & 100 & 8.5 & 7.5 & 8.5 & 7.5 & 0 & 12.2 \\
3 & 150 & 12.2 & 10.8 & 9.5 & 12.3 & 0.02 & 12.2 \\
4 & 200 & 15.9 & 15.2 & 10.3 & 12.4 & 0.08 & 12.3 \\
5 & 250 & 21.4 & 19.3 & 11.2 & 12.6 & 0.15 & 12.4 \\
6 & 300 & 24.7 & 22.8 & 11.6 & 12.8 & 0.20 & 12.6 \\
7 & 350 & 28.8 & 26.6 & 12.2 & 13 & 0.26 & 12.8 \\
8 & 400 & 34.8 & 32.4 & 13.1 & 13.4 & 0.37 & 13.1 \\
9 & 450 & 37.9 & 34.4 & 13.8 & 13.8 & 0.42 & 13.5 \\
10 & 500 & 42.5 & 38.5 & 14.1 & 13.9 & 0.50 & 13.6 \\
11 & 550 & 45.8 & 41.8 & 14.6 & 14.1 & 0.56 & 13.9 \\
12 & 600 & 49.6 & 45.2 & 15.3 & 14.4 & 0.65 & 14.1 \\
\hline
\end{tabular}


Data obtained from the measurement result was that the rotation speed was from 50 to $600 \mathrm{rpm}$. With this rotation speed, the highest voltage obtained in $600 \mathrm{rpm}$ and $4 \mathrm{~mm}$ air gap was 49.6 Volt AC and generator work frequency was in $50 \mathrm{~Hz}$.

In air gap variation of $4 \mathrm{~mm}$, the generator was able to charge battery in minimum rotation of 300 rpm with voltage produced was 12.8 Volt DC and current flowed was 0.20 Ampere.

Table 3.

Generator Test Result with 3 mm Air Gap

\begin{tabular}{cccc|cccc}
\hline & & \multicolumn{2}{c|}{$\begin{array}{c}\text { Output Voltage with } \\
\text { No Load }\end{array}$} & \multicolumn{3}{c}{ Output Voltage Connected with Battery } \\
\cline { 3 - 7 } No & Rpm & Volt AC & Volt DC & Volt AC & Volt DC & Arus (A) & $\begin{array}{c}\text { Volt } \\
\text { Battery }\end{array}$ \\
\cline { 3 - 7 } & & 4.6 & 4.2 & 4.6 & 4.2 & 0 & 12.1 \\
1 & 50 & 9.3 & 8.1 & 9.3 & 8.1 & 0 & 12.1 \\
2 & 100 & 12.9 & 11.1 & 9.4 & 12.1 & 0.04 & 12.1 \\
3 & 150 & 18.8 & 16.6 & 10.4 & 12.2 & 0.11 & 12.2 \\
4 & 200 & 22.4 & 19.6 & 10.8 & 12.3 & 0.16 & 12.3 \\
5 & 250 & 26 & 22.9 & 11.4 & 12.6 & 0.22 & 12.6 \\
6 & 300 & 31.2 & 27 & 12.3 & 12.9 & 0.32 & 12.9 \\
7 & 350 & 35.9 & 31.9 & 13 & 13.3 & 0.43 & 13.3 \\
8 & 400 & 39.9 & 35.4 & 13.3 & 13.4 & 0.44 & 13.4 \\
9 & 450 & 45.1 & 40 & 14.1 & 13.8 & 0.56 & 13.8 \\
10 & 500 & 48.6 & 43.2 & 14.6 & 14.2 & 0.61 & 14.2 \\
11 & 550 & 53.7 & 47.7 & 15.2 & 14.5 & 0.70 & 14.5 \\
12 & 600 & \multicolumn{7}{c}{}
\end{tabular}

Data obtained from the measurement result was that the rotation speed was from 50 to $600 \mathrm{rpm}$. With this rotation speed, the highest voltage obtained in $600 \mathrm{rpm}$ and $3 \mathrm{~mm}$ air gap was 53.7 Volt AC and generator work frequency was in $50 \mathrm{~Hz}$.

In air gap variation of $3 \mathrm{~mm}$, the generator was able to charge battery in minimum rotation of 300 rpm with voltage produced was 12.6 Volt DC and current flowed was 0.22 Ampere.

Table 4.

Generator Test Result with 2 mm Air Gap

\begin{tabular}{cccc|cccc}
\hline \multirow{2}{*}{ No } & \multirow{2}{*}{ Rpm } & \multicolumn{2}{c|}{$\begin{array}{c}\text { Output } \\
\text { Voltage with No Load }\end{array}$} & \multicolumn{3}{c}{ Output Voltage Connected with Battery } \\
\cline { 3 - 7 } & & Volt AC & Volt DC & Volt AC & Volt DC & Arus (A) & Volt Baterai \\
\hline 1 & 50 & 5 & 4.6 & 5 & 4.6 & 0 & 0 \\
2 & 100 & 11.2 & 9.8 & 8.7 & 12.2 & 0.01 & 12.3 \\
3 & 150 & 14.2 & 12.4 & 9.2 & 12.3 & 0.04 & 12.3 \\
4 & 200 & 19.4 & 17 & 10.5 & 12.4 & 0.12 & 12.4 \\
5 & 250 & 23.5 & 20.7 & 10.9 & 12.5 & 0.17 & 12.5 \\
6 & 300 & 29.3 & 25.7 & 11.6 & 13 & 0.23 & 13 \\
7 & 350 & 34.1 & 30.1 & 12.4 & 13.4 & 0.32 & 13.3 \\
8 & 400 & 38.4 & 34 & 12.5 & 13.5 & 0.36 & 13.4 \\
9 & 450 & 44.4 & 39.3 & 13.0 & 13.7 & 0.45 & 13.6 \\
10 & 500 & 48.8 & 43.3 & 13.6 & 14 & 0.53 & 13.9 \\
11 & 550 & 53.5 & 47.6 & 14.1 & 14.2 & 0.61 & 14.1 \\
12 & 600 & 59 & 52.5 & 14.8 & 14.8 & 0.68 & 14.8 \\
\hline
\end{tabular}

Data obtained from the measurement result was that the rotation speed was from 50 to $600 \mathrm{rpm}$. With this rotation speed, the highest voltage obtained in $600 \mathrm{rpm}$ and $2 \mathrm{~mm}$ air gap was 59 Volt AC and generator work frequency was in $50 \mathrm{~Hz}$.

In air gap variation of $2 \mathrm{~mm}$, the generator was able to charge battery in minimum rotation of 300 rpm with voltage produced was 13 Volt DC and current flowed was 0.23 Ampere. 
JEEMECS (Journal of Electrical Engineering, Mechatronic and Computer Science

Vol. 3, No. 1, February 2020, pp. 55-64

d. https://doi.org/10.26905/jeemecs.v3i1.3999

\subsection{Analysis of Voltage Distinction to Air Gap Variation}

Table 5.

Result of Highest Output Voltage in Every Different Air Gap

Highest Voltage Distinction Inter-air Gap

\begin{tabular}{ccccc}
\hline No & Air Gap Distance & Rpm & Volt AC & Volt DC \\
\hline 1 & $2 \mathrm{~mm}$ & 600 & 59 & 52,5 \\
2 & $3 \mathrm{~mm}$ & 600 & 53,7 & 47,7 \\
3 & $4 \mathrm{~mm}$ & 600 & 49,6 & 45,2 \\
4 & $5 \mathrm{~mm}$ & 600 & 48,5 & 44,4 \\
\hline
\end{tabular}

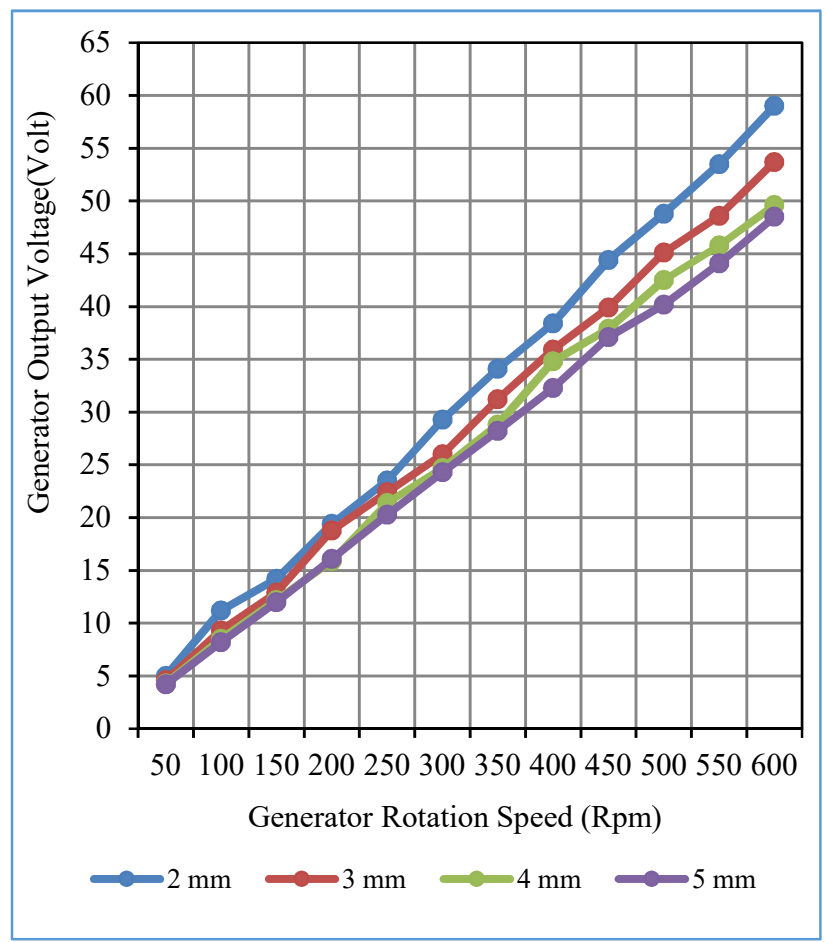

Fig. 4. Generator Output Voltage with Air Gap Distance Variation

\subsection{Comparison of Planned Voltage with Test Result}

Table 6.

Distinction Results between Planned Voltage and Test Results

\begin{tabular}{ccccc}
\hline No & $\begin{array}{c}\text { Air } \\
\text { Gap Distance }\end{array}$ & Rpm & Planned Voltage & Test Voltage \\
\hline 1 & $2 \mathrm{~mm}$ & 600 & 69,8 & 59 \\
2 & $3 \mathrm{~mm}$ & 600 & 62,22 & 53,7 \\
3 & $4 \mathrm{~mm}$ & 600 & 56 & 49,6 \\
4 & $5 \mathrm{~mm}$ & 600 & 54,68 & 48,5 \\
\hline
\end{tabular}




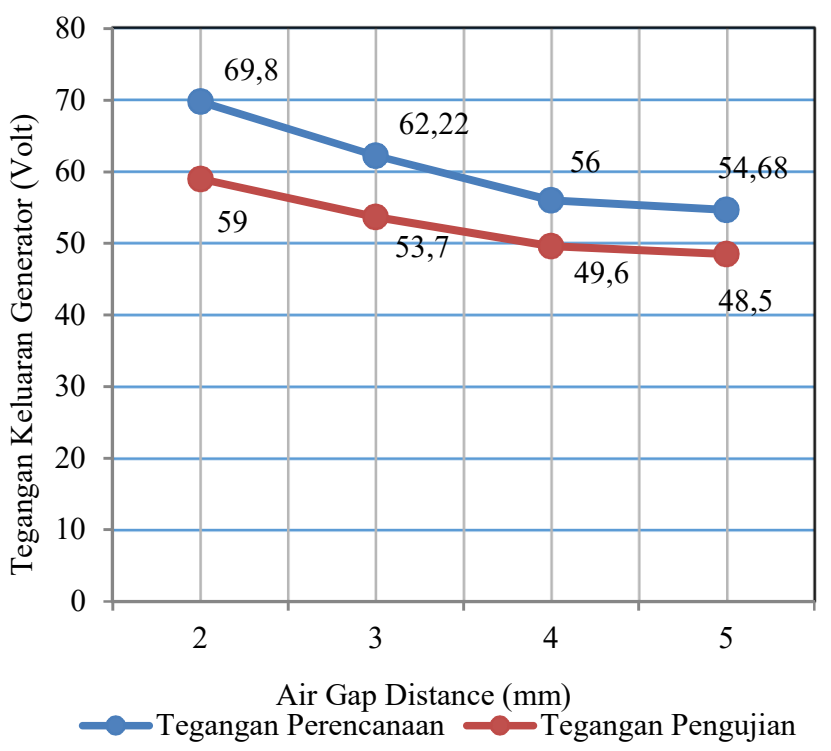

Fig. 5. Graphic for Generator Output Voltage from the Calculation Result of Planning and Testing

There were voltage distinctions between planning and test results. Planned voltages were higher than test results due to losses - losses due to material quality, and lack of precision in designing.

\section{Conclusion}

The tests on multi-stage axial flux permanent magnet generator used two stator discs and three rotor discs with air gap variation between different rotor and stator. There were six distinctive variations of air gap which were $2 \mathrm{~mm}, 3 \mathrm{~mm}, 4 \mathrm{~mm}$ and $5 \mathrm{~mm}$. Every air gap distintion was connected to stator sequences in series.

The test results with $2 \mathrm{~mm}$ air gap produced voltage of 59 Volt AC, $3 \mathrm{~mm}$ air gap produced voltage of 53.7 Volt AC, $4 \mathrm{~mm}$ air gap produced voltage of 49.6 Volt $\mathrm{AC}$, and $5 \mathrm{~mm}$ produced voltage of 48.5 Volt AC. Based on these tests, it could be concluded that air gap distance was inversely proportional to output voltage; the bigger air gap value that was provided, the smaller generator output voltage that was produced 


\section{References}

[1] B. A. Nasir, "Design considerations of micro-hydro-electric power plant," Energy Procedia, vol. 50, pp. 19-29, 2014.

[2] Y. R. Pasalli and A. B. Rehiara, "Design Planning of Micro-hydro Power Plant in Hink River," Procedia Environ. Sci., vol. 20, pp. 55-63, 2014.

[3] V. Goudar, Z. Ren, P. Brochu, M. Potkonjak, and Q. Pei, "Optimizing the output of a human-powered energy harvesting system with miniaturization and integrated control,” IEEE Sens. J., vol. 14, no. 7, pp. 2084-2091, 2014.

[4] A. Khaledian and M. Aliakbar Golkar, "Analysis of droop control method in an autonomous microgrid," J. Appl. Res. Technol., vol. 15, no. 4, pp. 371-377, 2017.

[5] P. A. Michael and C. P. Jawahar, "Design of $15 \mathrm{~kW}$ Micro Hydro Power Plant for Rural Electrification at Valara,” Energy Procedia, vol. 117, pp. 163-171, 2017.

[6] D. Zappalá, N. Sarma, S. Djurović, C. J. Crabtree, A. Mohammad, and P. J. Tavner, "Electrical \& mechanical diagnostic indicators of wind turbine induction generator rotor faults," Renew. Energy, vol. 131, pp. 14-24, 2019.

[7] E. Cetin and F. Daldaban, "Analyzing distinctive rotor poles of the axial flux PM motors by using 3DFEA in view of the magnetic equivalent circuit," Eng. Sci. Technol. an Int. J., vol. 20, no. 5, pp. 1421$1429,2017$.

[8] M. R. Minaz and M. Çelebi, "Design and analysis of a new axial flux coreless PMSG with three rotors and double stators," Results Phys., vol. 7, pp. 183-188, 2017.

[9] S. A. Shufat, E. Kurt, C. Cinar, F. Aksoy, A. Hançerlioğulları, and H. Solmaz, "Exploration of a Stirling engine and generator combination for air and helium media," Appl. Therm. Eng., vol. 150, no. January, pp. 738-749, 2019.

[10]D. P. Arnold, "Review of microscale magnetic power generation," IEEE Trans. Magn., vol. 43, no. 11, pp. 3940-3951, 2007.

[11]H. Jaber, M. Khaled, T. Lemenand, and M. Ramadan, "Effect of generator load on hybrid heat recovery system," Case Stud. Therm. Eng., vol. 13, no. November 2018, p. 100359, 2019.

[12] M. Niroomand and H. R. Foroughi, "A rotary electromagnetic microgenerator for energy harvesting from human motions,” J. Appl. Res. Technol., vol. 14, no. 4, pp. 259-267, 2016.

[13] A. N. Singh, W. Doorsamy, and W. Cronje, “Thermographical analysis of turbo-generator rotor," Electr. Power Syst. Res., vol. 163, no. June, pp. 252-260, 2018.

[14]E. B. Kengne Signe, O. Hamandjoda, and J. Nganhou, "Methodology of Feasibility Studies of MicroHydro power plants in Cameroon: Case of the Micro-hydro of KEMKEN," Energy Procedia, vol, 2017. 119, pp. 17-28

[15] Abdul Multi, Iwa Garniwa, and Uno Bintang Sudibyo, "Determining the Air Gap Length. of an Axial Flux Wound Rotor Synchronous Generator", Makara Seri Teknologi, 2013, 17(2): 87-93 
This page intentionally left blank 